\title{
ORIENTAÇÕES SOBRE HIGIENE E QUALIDADE DO LEITE NO IFRS CAMPUS SERTÃO
}

\author{
Carla Verônica Vasconcellos Diefenbach ${ }^{1}$ \\ ORCID: 0000-0002-3517-9966 \\ Elísio de CAmargo Debortoli ${ }^{2}$ \\ ORCID: 0000-0001-5594-2810 \\ Darlan Teilor Dirings Cesca ${ }^{3}$ \\ ORCID: 0000-0003-3066-5129 \\ Cleimar Grespan ${ }^{3}$ \\ ORCID: 0000-0003-1148-2730 \\ Tamara Cecchin Biondo 3 \\ ORCID: 0000-0003-0963-8513
}

Resumo: A qualidade do leite é influenciada por fatores zootécnicos associados ao manejo e armazenagem do leite. Tal fato tem sido foco de preocupação entre produtores e consumidores nos últimos anos. Sendo assim, a ação de extensão teve como objetivo identificar fatores limitantes para a higiene e qualidade do leite, propondo estratégias para a melhoria da produção leiteira em propriedades rurais de pequeno porte. $\mathrm{O}$ trabalho foi desenvolvido no município de Sertão/RS e em outros 12 municípios limítrofes no período entre 2015 e 2018. Foi preparado um roteiro diagnóstico para orientar as observações in loco, verificando assim, as condições de produção relacionadas à higiene e qualidade do leite. Os resultados indicaram

1 Médica veterinária, doutora em Educação, professora titular no Instituto Federal de Educação, Ciência e Tecnologia do Rio Grande do Sul - Campus Sertão. E-mail: carla.diefenbach@sertão.ifrs. edu.br.

2 Médico veterinário, doutor em Ciência Animal, professor associado no Instituto Federal de Educação, Ciência e Tecnologia do Rio Grande do Sul - Campus Sertão. E-mail: elisio.debortoli@sertão. ifrs.edu.br.

3 Acadêmicos do curso de Zootecnia no Instituto Federal de Educação, Ciência e Tecnologia do Rio Grande do Sul - Campus Sertão. E-mails: darlan.dirings@gmail.com; cleimar.grespan@gmail.com; tamaracbiondo@gmail.com. 
carência de informações e falta de assistência técnica qualificada nas propriedades leiteiras, em especial, a falta de treinamento da mão de obra, dificuldades de infraestrutura e uso de produtos ou de procedimentos inadequados. Diante disso, foram realizadas orientações para o esclarecimento dos produtores sobre a importância de melhorias no manejo e como algumas mudanças de atitudes poderiam influenciar positivamente a higiene e qualidade do leite.

Palavras-chave: Bovinocultura de leite. Manejo da ordenha. Projeto de extensão.

\title{
GUIDELINES ON HYGIENE AND MILK QUA- LITY IN IFRS GAMPUS SERTÃO
}

\begin{abstract}
Milk quality is influenced by zootechnical factors associated with milk management and storage. This fact has been a focus of concern among producers and consumers in recent years. Therefore, the extension action had as objective to identify limiting factors for milk hygiene and quality, proposing strategies for the improvement of dairy production in small farms. The work was developed in the municipality of Sertão / RS and in 12 other neighboring municipalities in the period between 2015 and 2018. A diagnostic roadmap was prepared to guide the observations in loco, thus verifying the production conditions related to hygiene and milk quality. The results indicated lack of information and lack of qualified technical assistance in dairy farms, in particular, lack of training of the workforce, difficulties in infrastructure and use of products or inadequate procedures. Therefore, guidelines were made for the clarification of the producers on the importance of improvements in management and how some changes of attitudes could positively influence milk hygiene and quality. Keywords: Milk farms. Milk handling. Extension project.
\end{abstract}

\section{ORIENTACIONES SOBRE HIGIENE Y CALI- DAD DE LA LECHE NO IFRS CAMPUS SERTÃO}

Resumen: La calidad de la leche es influenciada por factores zootécnicos asociados AL manejo
y almacenamiento de la leche. Este hecho ha sido foco de preocupación entre los productores
y consumidores en los últimos años. Por lo tanto, la acción de extensión tuvo como objetivo
identificar factores limitantes para higiene y calidad de la leche, proponiendo estratégias para
la mejora de la producción lechera em propiedades rurales de pequeño porte. El trabajo fue
desarrollado en município de Sertão/RS y en otros 12 municipios limítrofes en el período
entre 2015 y 2018 . Fue preparado un itinerario diagnostico para orientar las observaciones
in loco, verificando así, las condiciones de la producción relacionadas a la higiene y calidad
de la leche. Los resultados indicaram carencia de informaciones y falta de asistencia técnica
calificada en las propiedades lecheras, en especial, a falta de entrenaminto de la mano de
obra, dificultades de infraestructura y uso de productos o de procedimientos inadecuados.
Por lo tanto, se realizaron orientaciones para el esclarecimientos de los productores sobre 
la importancia de las mejoras en lo manejo y cómo algunos cambios de atictudes podrían influenciar positivamente a higiene y calidad de la leche.

Palabras claves: Bovinocultura de la leche. Proyetos del Extensión. Manejo del ordeño.

\section{INTRODUÇÃO}

A qualidade do leite é influenciada por fatores zootécnicos associados ao manejo, alimentação e armazenagem. Tal fato tem sido foco de preocupação entre produtores e consumidores nos últimos anos. Atualmente, na região Norte do Rio grande do Sul a cadeia produtiva do leite está sendo fomentada e demonstra expansão. No entanto, diante de dificuldades encontradas, constata-se a saída da atividade por parte dos pequenos produtores, ficando os rebanhos concentrados em propriedades com maior escala. Além disso, torna-se necessária melhor gestão e controle leiteiro para assim obter dados confiáveis do rebanho para auxiliar na tomada de decisão quanto ao manejo adequado dos animais.

A produção de leite em condições de higiene e sanidade inadequadas afeta negativamente o rendimento para a produção de derivados lácteos, causando perdas para as indústrias que processam o leite, além de não assegurar a qualidade do produto final. Por isso, é importante que a legislação específica seja seguida, pois assim, o consumidor poderá acessar um produto com qualidade assegurada. Da mesma maneira, a indústria não terá de enfrentar problemas na produção e os consumidores ficarão satisfeitos com os produtos (MELO, 2016).

Os consumidores exigem cada vez mais informações sobre os produtos adquiridos. E a garantida de qualidade dos produtos só pode ser atingida se a matéria prima for produzida de maneira higiênica, sem adulterações, proveniente de um rebanho saudável e livre de doenças. Assim as normativas do Ministério da Agricultura, Pecuária e Abastecimento (MAPA) buscam orientar e regulamentar os processos de produção e obtenção de leite para garantir que o produto final apresente qualidade, segurança alimentar e valor agregado.

Alguns fatores são relevantes e devem receber certa atenção, pois podem interferir na qualidade do leite, como a saúde dos animais, limpeza dos utensílios utilizados na ordenha, higiene dos tetos e úbere, cautela na coleta de amostras para análise, alimentação adequada e bem-estar oferecidos aos animais. 
Para obtermos uma melhoria na produção devemos levar em consideração vários aspectos da produção leiteira, o conhecimento técnico de práticas que influenciam a composição e a qualidade do leite, permitindo a realização de ações preventivas de monitoramento e controle, desde o momento da ordenha e o rápido resfriamento, passando pelo transporte isotérmico, até a indústria e seu processamento adequado, para que chegue ao consumidor um produto de alta qualidade, de aceitação, tanto no mercado interno, quanto no externo.

Propriedades leiteiras fornecem benefícios econômicos e sociais aos produtores e à comunidade. A cadeia produtiva do leite vêm se destacando como atividade independente nos sistemas de produção animal da região Norte do Rio Grande do Sul. Sendo assim, neste setor de produção animal, o produtor possui autonomia para a tomada de decisão quanto à escala, sistema de produção e manejos que deseja adotar.

Diante desse contexto, surgiu o interesse em desenvolver um projeto de extensão na área de bovinocultura de leite para o envolvimento dos discentes de graduação em ações de extensão, como prática essencial na formação de maneira mais integral.

Sendo assim, o presente estudo teve como objetivo identificar fatores limitantes para a higiene e qualidade do leite, propondo estratégias para a melhoria da produção leiteira em propriedades rurais de pequeno porte na região do entorno do IFRS Campus Sertão. Visto que a cadeia produtiva do leite relaciona-se principalmente na composição de sólidos, higiene e sanidade, para que o produtor seja bonificado pela qualidade do produto. $\mathrm{O}$ trabalho foi desenvolvido em propriedades leiteiras do município de Sertão/RS e em outros 12 municípios limítrofes durante no período entre 2015 e 2018.

\section{CARACTERÍSTICAS DE PRODUÇÃO E QUALIDADE DO LEITE NO BRASIL}

Segundo o MAPA (2011), entende-se por leite o produto proveniente da ordenha completa e contínua, em condições de higiene adequadas, de vacas saudáveis, bem nutridas e em homeostase. O leite é um alimento que satisfaz todas as necessidades de um recém-nascido, é composto de proteínas, gordura, carboidrato, sais minerais e vitaminas, ou seja, apresenta características nutricionais que faz um dele um alimento consumido ao longo da vida do ser humano (MULLER, 2002). 
A produção de leite está difundida em todo o território brasileiro, sendo mais de um milhão de propriedades dedicadas a produzir esta matéria prima (VILELA et al., 2002). Em 2016, a produção brasileira foi de 23.169 .654 mil litros de leite cru. No ano seguinte, a produção nacional aumentou, chegando a 24.116.947 mil litros de leite somando uma variação de 4,1\% a mais em 2017. Desse total adquirido nas fazendas 24.080 .265 foram industrializados pelos laticínios (IBGE, 2016).

A cadeia produtiva do leite está alicerçada em três pilares produtivos: genética, manejo e nutrição dos animais. A genética é um fator interno e individual do animal, porém depende de fatores externos como a alimentação e o manejo para expressar seu potencial máximo. Como se trata de uma atividade que visa lucro econômico para a fazenda, é necessário que se tenha noções básicas de controle financeiro e gerencial para que não haja prejuízos, principalmente se tratando dos ingredientes da alimentação das vacas, pois este é o maior componente dos custos de produção de leite (CHAPAVAL, 2000).

A obtenção de leite de qualidade é dependente de vários fatores como o estado sanitário do rebanho, limpeza dos equipamentos e utensílios de ordenha, a higiene do local, bem como da qualidade da água utilizada nos processos de sua obtenção (RAMIRES et al., 2009). A gordura e a proteína são componentes que variam de acordo com a raça das vacas e ainda pode ocorrer variação de animal para animal, mesmo estas sendo de mesma raça (GONZÁLEZ, 2001).

Vacas leiteiras de alta produção após o parto exigem níveis de nutrientes superiores para a síntese do leite. É indispensável que ocorra o consumo de alimentos com alta densidade energética para que esses nutrientes sejam supridos adequadamente. Porém, neste momento mesmo com maior necessidade, a vaca apresenta menor consumo de matéria seca, não obtendo a quantidade necessária de nutrientes, resultando em um balanço energético negativo. Por isso, é fundamental uma correta formulação de rações para animais nestas condições para que haja o suprimento das exigências energéticas de forma correta (VARGAS et al., 2002).

Os alimentos compõe a ferramenta básica para que seja possível alterar a composição do leite, principalmente porque os nutrientes consumidos formam, diretamente ou indiretamente, os principais componentes sólidos do leite. Entretanto, não é possível garantir, ao fornecer determinado ingrediente na alimentação das vacas, que o mesmo vai estar presente na mesma proporção no leite. Um exemplo produtivo clássico ocorre com a adição de gordura 
na dieta das vacas que, na maioria das vezes, provoca a diminuição do teor de gordura do leite (PEDROSO, 2006).

A proteína do leite bovino contém cerca de $80 \%$ de caseína e $20 \%$ de proteínas do soro. As frações do soro são compostas por beta-lactoglobulina, alfa-lactoalbumina, albumina do soro bovino (BSA) e imunoglobulinas. Já a gordura do leite é constituída por cerca de $98 \%$ de triglicerídeos com grandes quantidades de ácidos graxos saturados, por causa da hidrogenação parcial ou completa ocasionada pela forma de degradação e absorção dos alimentos pelos bovinos. O leite ainda é uma fonte abundante de cálcio e fósforo, mas também contém magnésio, potássio, cloreto e sódio (HARAGUCHI et al., 2006; REECE, 2017).

A água é o componente de maior proporção no leite, ocupando 87\%, e o responsável por manter os outros componentes dissolvidos, afastados ou emulsionados compondo o leite. Os outros componentes apresentam-se em menores porcentagens, sendo eles: 3,9\% de gordura, 3,2\% de proteínas, $0,9 \%$ de minerais e vitaminas, lactose com $4,6 \%$ a qual é o carboidrato encarregado de reger o volume de leite que é produzido no úbere (OHIO et al., 2010). A lactose é o principal glicídio presente no leite, a qual é fundamental na síntese do leite, pois atrai as moléculas de água para as células epiteliais mamárias (GONZÁLEZ, 2001).

Com a bonificação pela qualidade do leite ou desconto pelo não cumprimento dos padrões exigidos pelas empresas beneficiadoras de leite, os produtores tendem a adequar o sistema de produção às leis atuais, assim como buscar conhecimento e aumentar o nível tecnológico de suas propriedades (MARTINS et al., 2015). A referência aplicada para pagamento por qualidade do leite é a contagem de células somáticas (CCS), pois a mesma pode ser indicativo da saúde do rebanho (PEIXOTO et al., 2016). O leite apresenta células epiteliais e células de defesa (macrófagos, linfócitos e neutrófilos), que são indicadas pela (CCS), a qual pode variar de acordo com o estágio de lactação, a idade da vaca, a estação do ano, o tamanho do rebanho, o nível de produção de leite e o estado de infecção intramamária (MARTINS et al., 2015).

O leite com altas contagens de células somáticas é derivado de vacas que apresentam infecção na glândula mamária, o que traz como consequência o declínio na produção, modificações físico-químicas do leite e menor tempo de prateleira do produto após processamento da indústria (ANDRADE et al., 2009). A elevação da contagem de células somáticas é o indicativo da presença 
de mastite subclínica, porém este tipo de mastite não é muito perceptível, não permitindo que o produtor observe sua presença. A mastite subclínica leva o rebanho ou animal a uma perda na produção de leite e afeta a qualidade do mesmo. Deste modo pode-se observar o quanto é relevante o nível de CCS para identificar a saúde do rebanho (DURR, 2012). Utilizar de boas práticas na ordenha garante que o leite mantenha qualidade, sendo que não são necessários investimentos em infraestrutura e uma vez incorporada na rotina da ordenha é fácil de serem seguidas (MATSUBARA et al., 2011).

Quanto mais especializado for o sistema de produção maior será a produtividade de leite por animal e, possivelmente, menor a contagem de células somáticas, devido ao melhor manejo e nutrição do rebanho, higiene do ambiente e equipamentos, cuidado na coleta e armazenagem do leite (ZANELA et al., 2006).

\section{DESCRIÇÃO DA AÇÃO DE EXTENSÃO E OBSERVAÇÕES IN LOCO}

O IFRS Campus Sertão, ao estimular ações de extensão em propriedades rurais nas regiões de origem/inserção de seus discentes, possibilita que os alunos mantenham vínculos com suas comunidades locais e, ao mesmo tempo consigam transferir conhecimentos teóricos aprendidos na Instituição, promovendo aprendizagem organizacional e atuando como agentes indutores do desenvolvimento local.

Após realizados estudos teóricos para desenvolver aprofundamento de conhecimentos sobre o tema, identificando os problemas mais comuns relacionados à higiene do leite e elaboração de um roteiro diagnóstico, seguiu-se para o contato direto com os envolvidos. Na visita in loco, foram verificadas as condições que se encontravam as propriedades quanto à higiene e qualidade do leite. Para entender a situação do leite das propriedades visitadas, buscou-se indicadores da qualidade do leite das indústrias processadoras e com isso entendeu-se as os objetivos buscados pelos produtores. Além disso, foi realizado acompanhamento das práticas de ordenha desenvolvida pelo pecuarista na sala de ordenha, e assim, registrando os principais problemas de execução, recomendando propostas de melhoria da qualidade do leite. 
Os principais problemas encontrados, nas propriedades visitadas, relacionam-se ao manejo da ordenha, falta de preparação do úbere antes da ordenha, ausência da realização de procedimentos como a desinfecção dos tetos antes da ordenha com o produto pré-dipping. seguido da secagem com papel toalha descartável. Após a ordenha a desinfecção dos tetos com o produto pós-dipping. Utilização de produtos ou procedimentos inadequados para realização da higiene dos equipamentos de ordenha. A inexistência da realização do Teste da caneca do fundo preto e Teste CMT (Califórnia Mastite Teste) para diagnosticar infeção no úbere ocasionada pela mastite clínica e subclínica. O processo de refrigeração do leite deve ser imediato após a coleta, a fim de evitar a rápida proliferação de microrganismos. Essas práticas não efetuadas ou realizadas de forma incorreta, podem afetar a qualidade do leite.

As propriedades visitadas possuem produção acima de duzentos litros diários e contam com outras atividades, como produção de grãos, especialmente a sojicultora. Há também propriedades destinadas somente a produção de leite, as quais representam 30\% do total dos sistemas de produção visitados. Quanto a estrutura das propriedades, 54,5\% dos produtores de leite realizam ordenha na sala de ordenha, $36,4 \%$ realizam a ordenha dos animais em estábulos enquanto $9,1 \%$ realizam em curral coberto, $50 \%$ faz o uso de transferidores, $40 \%$ ordenha canalizada e $10 \%$ bombas até 260 litros.

Todos os sistemas de produção visitados realizam ordenha duas vezes ao dia. Durante a ordenha $50 \%$ não possuem sequência estabelecida, $40 \%$ conforme a fase de lactação e condição sanitária, levando em consideração também os testes de CCS e CBT e 50\% divide o plantel em dois sendo animais de $1^{\text {a }}$ cria e o restante do rebanho, $20 \%$ não possuem sequência definida. Tratando-se de alimentação durante a ordenha $60 \%$ não alimenta os animais enquanto $40 \%$ os alimenta. No manejo de limpeza dos tetos, verificou-se em todas as propriedades é realizada a limpeza dos tetos antes da ordenha, já no pré-dipping $63,6 \%$ faz o uso de espuma, $9,1 \%$ Iodo, $18,2 \%$ não realiza e $9,1 \%$ realiza outros tipos de higienização.

A secagem dos tetos é realizada de forma incorreta através de panos por $45,5 \%$ dos produtores, $45,5 \%$ realiza secagem com papel toalha e $9,1 \%$ dos mesmos não realizam a secagem. Quando questionados quanto ao teste da caneca de fundo preto ou chão preto, a maioria dos pecuaristas não realiza correspondendo a 54,5\%, e 45,5\% realizam, referente ao CMT 63,3\% não o realiza e $36,4 \%$ realiza quinzenalmente ou quando consideram necessário. No 
pós-dipping, 72,7\% utiliza Iodo, 9,1\% Clorexidina e 18,2\% não realiza uso de produtos. Verificou-se também que $81,8 \%$ dos animais são mantidos em pé após a ordenha e 18,2\% não. O principal problema encontrado nas propriedades são mamitelmastite representando 90,9\% e problemas de ligamento 9,1\%.

Se os produtores conseguirem melhorar as diversas dificuldades enfrentadas no dia a dia, poderão elevar consideravelmente a qualidade do leite. Consequentemente, eles conseguirão uma maior renda mensal, já que a maioria das indústrias remunera o leite pela qualidade. Baseando-se nestes dados foi sugerido um acompanhamento durante a ordenha para uma orientação aos pecuaristas, a fim de resolver ou amenizar seus problemas.

\section{GONGLUSÃO}

Esta ação de extensão buscou motivar os discentes oriundos de regiões produtoras de bovinos de leite a aprofundar seus estudos sobre o tema e, concomitante ao seu processo formativo, desenvolver ações visando a melhoria das condições da produção, do trabalho e da renda em suas comunidades de origem.

Além disso, buscou proporcionar a integração teórico-prática contemplando o tripé ensino-pesquisa-extensão. As vivências nas comunidades e a troca de experiências com os produtores proporcionou aos discentes o desenvolvendo de habilidades de comunicação, postura e de relações interpessoais.

Com as visitas e o diagnóstico nos sistemas de produção, constatou-se carência de informações e falta de assistência técnica qualificada nas propriedades leiteiras, as quais poderiam influenciar positivamente a higiene e qualidade do leite.

O projeto proporcionou aos envolvidos muito aprendizado, agregação de experiências e crescimento profissional. Além disso, os envolvidos fizeram uma interação da extensão universitária com a comunidade, podendo auxiliar em muitas propriedades nas principais deficiências de higiene que estão ligadas aos problemas de treinamento de mão de obra, dificuldades de infraestrutura e uso de produtos ou de procedimentos inadequados.

\section{REFERÊNCIAS}


ANDRADE, U.; HARTMANN, W.; MASSON, M. L. Isolamento microbiológico, contagem de células somáticas e contagem bacteriana total em amostras de leite. Ars Veterinária, v. 25, n. 3, p. 129-135, 2010.

CHAPAVAL, L. Leite de qualidade: manejo reprodutivo, nutricional e sanitário. Viçosa: Aprenda Fácil, 2000. 195.p.

DÜRR, J. W. Como produzir leite de qualidade. 4. ed. Brasília: SENAR, 2012. 44 p.

GONZÁLEZ F. H. D. Composição bioquímica do leite e hormônios da lactação. In: Uso do leite para monitorar a nutrição e o metabolismo de vacas leiteiras. Gráfica da Universidade Federal do Rio grande do Sul, Porto Alegre, 2001.

HARAGUCHI, F. K. et al. Proteínas do soro do leite: composição, propriedades nutricionais, aplicações no esporte e benefícios para a saúde humana. Revista de Nutrição, v. 19, n. 4, p. 479-88, 2006.

INSTITUTO BRASILEIRO DE GEOGRAFIA E ESTATÍSTICA - IBGE. Estatísticas Disponível em: https://www.ibge.gov.br/busca.html?searchword=bovinocultura\%20 de\%20 leite\&searchp hrase=all. Acesso em: 12 abr. 2018.

MARTINS, J. D., et al. Mastite subclínica em rebanhos leiteiros de propriedades rurais de Goiás. Revista Brasileira de Higiene e Sanidade Animal, v.9, n. 2, p. 206-214, 2015. MATSUBARA, M. T. et al. Boas práticas de ordenha para redução da contaminação microbiológica do leite no agreste de Pernambuco. Semina: Ciências Agrárias, v.32, n.1, p. 277-286, 2011.

MINISTÉRIO DA AGRICULTURA, PECUÁRIA E ABASTECIMENTO - MAPA. Instrução Normativa no. 62, de 29 de dezembro de 2011. Regulamentos técnicos de produção, identidade, qualidade, coleta e transporte de leite. Diário Oficial da União, Brasília, p. 6, 30 de dezembro de 2011.

MULLER, E. E. Qualidade do leite, células somáticas e prevenção da mastite. IN: SulLeite: Simpósio Sobre Sustentabilidade da Pecuária Leiteira na Região Sul do Brasil, v. 2, p. 206-217, 2002.

OHIO, M. et al. Princípios básicos para a produção de leite bovino. Curitiba: Imprensa da UFPR, 2010. 144p.

PEDROSO, A. M. Como a nutrição afeta a proteína do leite - parte 1. 2006. Disponível em: https://www.milkpoint.com.br/artigos/producao/como-a-nutricao-afeta-a-proteina-doleite-parte-1-30027n.aspx Acesso em: 14 de jun. 2018.

PEIXOTO A.L. et al. Influência do tipo de ordenha e do armazenamento do leite sobre a composição química, contagem de células somáticas e contagem bacteriana total. Revista do Instituto de Laticínios Cândido Tostes, Juiz de Fora, v. 71, n. 1, p. 10-18, 2016. RAMIRES, C.H. et al. Influência da qualidade microbiológica da água sobre a qualidade do leite. Archives of Veterinary Science, v.14, n.1, p.36-42, 2009.

REECE, W. O. Fisiologia dos animais domésticos. 13. ed. Rio de Janeiro: Guanabara Koogan, 2017. 
VARGAS, L. H., et al. Adição de lipídios na ração de vacas leiteiras: parâmetros fermentativos ruminam produção e composição do leite, Revista Brasileira de Zootecnia, v. 31, n.1, p. 522-529, 2002.

VILELA, D. et al. Políticas para o leite no Brasil: passado presente e futuro. Sul Leite Simpósio sobre Sustentabilidade da Pecuária Leiteira na Região Sul do Brasil, 2002, Maringá. Anais... Maringá: UEM/CCA/DZO-NUPEL, 2002.

ZANELA, M. B. et al. Qualidade do leite em sistemas de produção na região Sul do Rio Grande do Sul. Pesquisa Agropecuária Brasileira, v. 41, n. 1, p. 153-159, 2006. 